Review Article

\title{
The Clinical Value and Variation of Antithyroid Antibodies during Pregnancy
}

\author{
Chuyu Li, ${ }^{1,2,3}$ Jing Zhou, ${ }^{1,2,3}$ Zengshu Huang, ${ }^{1,2,3}$ Xinyao Pan, ${ }^{1,2,3}$ Wingting Leung, ${ }^{1,2,3}$ \\ Lijia Chen, ${ }^{1,2,3}$ Yanzhi Zhang, ${ }^{1,2,3}$ Lan Wang, ${ }^{1,2,3}$ Yizhen Sima, ${ }^{1,2,3}$ Hans-Jürgen Gober, ${ }^{4}$ \\ Na Zhang, ${ }^{1,2,3}$ Xuemin Qiu, ${ }^{1,2,3}$ Lisha Li, ${ }^{1,2,3}$ Liang Guan $\mathbb{D}^{5,6}$ and Ling Wang $\mathbb{D}^{1,2,3}$ \\ ${ }^{1}$ Laboratory for Reproductive Immunology, Hospital and Institute of Obstetrics and Gynecology, Shanghai Medical College, \\ Fudan University, Shanghai, China \\ ${ }^{2}$ The Academy of Integrative Medicine of Fudan University, Shanghai, China \\ ${ }^{3}$ Shanghai Key Laboratory of Female Reproductive Endocrine-Related Diseases, Shanghai, China \\ ${ }^{4}$ Department of Pharmacy, Neuromed Campus, Kepler University Hospital, 4020 Linz, Austria \\ ${ }^{5}$ Department of Nuclear Medicine, Ruijin Hospital, School of Medicine, Shanghai Jiaotong University, Shanghai, China \\ ${ }^{6}$ Department of Nuclear Medicine, Ruijin Hospital North, School of Medicine, Shanghai Jiaotong University, Shanghai, China
}

Correspondence should be addressed to Liang Guan; drliangguan@outlook.com and Ling Wang; dr.wangling@fudan.edu.cn

Chuyu Li and Jing Zhou contributed equally to this work.

Received 26 March 2020; Revised 15 July 2020; Accepted 31 July 2020; Published 22 October 2020

Academic Editor: Olav Lapaire

Copyright (C) 2020 Chuyu Li et al. This is an open access article distributed under the Creative Commons Attribution License, which permits unrestricted use, distribution, and reproduction in any medium, provided the original work is properly cited.

Antithyroid antibodies, which include thyroid-stimulating hormone receptor antibodies (TRAbs), thyroid peroxidase antibodies (TPOAbs), and thyroid globulin antibodies (TgAbs), are widely known for their tight association with thyroid autoimmune diseases. The variation in all three kinds of antibodies also showed different trends during and after pregnancy (Weetman, 2010). This article reviewed the the physiological changes, while focusing on the variation of thyroid antibodies concentration in women during and after pregnancy, and adverse consequences related to their elevation. Since abnormal elevations of these antithyroid antibodies may lead to adverse outcomes in both mothers and fetuses, special attention must be paid to the titer of the antibodies during pregnancy. The molecular mechanisms of the variations in those antibodies have yet to be explained. The frequency and timing of thyroid antibody measurement, as well as different reference levels, also remain to be elucidated.

\section{Introduction}

Progesterone and androgens are considered to have immunosuppressive effects and are therefore protective in autoimmune diseases, and estrogen is generally considered to be immunostimulatory and therefore pathogenic in autoimmune diseases [1]. Due to the effects of estrogen on the immune system, women are more susceptible to autoimmune thyroid diseases (AITDs), which include Hashimoto's thyroiditis (HT), Graves' disease (GD), and idiopathic hypothyroidism [2]. Positivity for antithyroid antibodies are tightly associated with AITDs, and the diagnoses of GD and HT highlight the importance of measuring thyroid-stimulating hormone receptor antibodies (TRAbs), thyroid peroxidase antibodies (TPOAbs), and thyroid globulin antibodies (TgAbs). For GD, it is recommended to measure TRAbs before stopping antithyroid drug (ATD) treatment and during pregnancy for accurate diagnosis/differential diagnosis $[3,4]$. TPOAbs and TgAbs are important indicators for determining the cause of primary hypothyroidism and the main indicators for diagnosing AITDs (including HT, atrophic thyroiditis, etc.) [5]. According to their effects on thyroid-stimulating hormone receptor (TSHR), TRAbs can be subdivided into TSHR-stimulating antibodies (TSAbs), TSHR-blocking antibodies (TBAbs), and neutral TRAbs (N-TRAbs), and these antibodies have different molecular structures and 


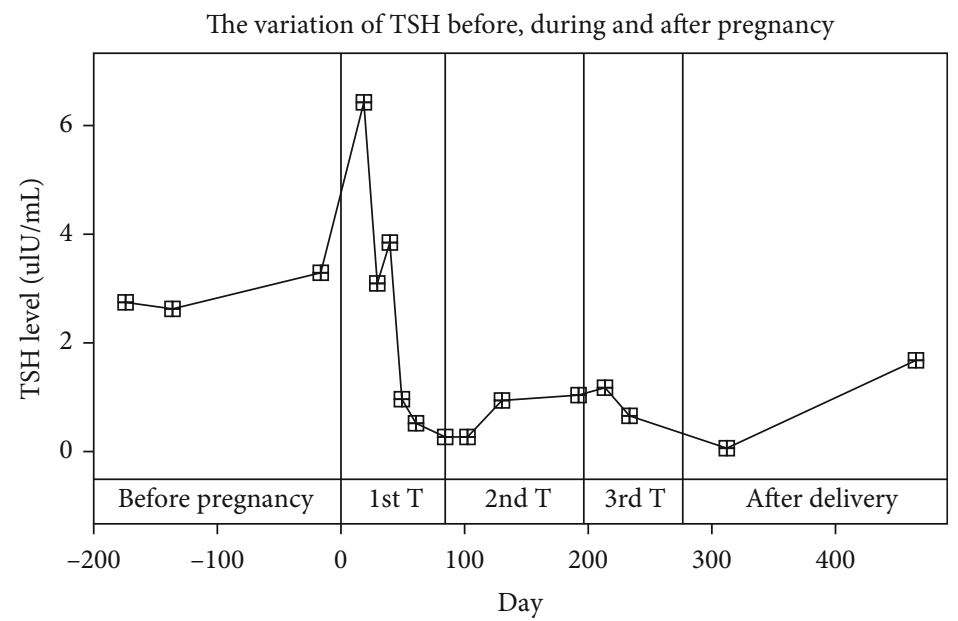

FIGURE 1: The variation in TSH before, during, and after pregnancy. The curve is a set of data from one patient at Ruijin Hospital. The delivery date of her infant was December 1, 2017. The last menstrual period was February 27, 2017, according to the gestational weeks and delivery date. The TSH level dropped to the lowest level at the end of the first trimester and then gradually ascended. T: trimester.

properties [6]. The abnormal elevation of TRAbs disturbs the thyroid function of both pregnant women and the fetus since they are capable of crossing the placental barrier freely [6]. Thyroid peroxidase (TPO), a membranebound enzyme, catalyzes the oxidation of iodide and the iodination of the tyrosyl residues of thyroglobulin. TPOAbs can bind to TPO and then damage the thyrocytes and cause hypothyroidism. The increase of TPOAbs is not scarce in the euthyroid population, and they are associated with major alterations in the course of pregnancy affecting the mother, fetus, and/or neonate [7]. Among the three kinds of antibodies, the $\mathrm{TgAb}$ is the earliest-discovered and it is mainly composed of IgG. It mainly attacks different antigenic determinants of thyroglobulin, which is located in the colloid of thyroid follicles. Since thyroglobulin is the intermediate of the thyroid hormones, TgAbs have a close association with both the synthesis and secretion of thyroid hormones [8]. TPOAb and $\mathrm{TgAb}$ are frequently present in the same individual. Some people think that the crossreactivity between $\mathrm{Tg}$ and TPO plays a role in the origin of thyroid autoimmunity [9]. Such cross-reactivity could include either the epitopes recognized by autoantibodies and/or the epitopes recognized by T cells that provide 'help' to B cells to differentiate and secrete antibodies [10]. Maternal thyroid disorders can damage maternal and fetal health during pregnancy, thus leading to adverse maternal, fetal, and obstetrical outcomes. Hypothyroidism is associated with gestational hypertension, anemia, preeclampsia, miscarriage, low fetal birth weight, fetal death, respiratory distress, congenital circulatory system malformations, and so on. Hyperthyroidism is associated with stillbirth, congestive heart failure, preterm labor, small for gestational age, and preeclampsia [11]. According to what we have described before, there is a strong connection among abnormal elevations of antithyroid antibodies, thyroid disease, and pregnancy.

It is generally considered that reduction in serum thyroid antibodies levels (TRAbs, TPOAbs, TgAbs) is the conse- quence of maternal immune tolerance during pregnancy. Relevant results have already been published. Researchers have found other major histocompatibility complex (MHC) molecules such as HLA-C, -E, -F, and HLA-G [12] instead of HLA class I and class II proteins to avoid allogeneic responses at the maternal-fetal interface. T-reg cells can also play a part in the depression of autoimmune responses in pregnancy. Estrogen has also been shown to be capable of dampening the function of $B$ cells in pregnancy [13].

In this review, we will cover the interaction among them, especially between abnormal elevations of antithyroid antibodies and pregnancy.

\section{Physiological Adjustment after Conception}

2.1. Human Chorionic Gonadotropin ( $h C G$ ). Increased hCG, which is produced by syncytiotrophoblasts, is one of the notable characteristics of early pregnancy. It can facilitate the synthesis as well as the secretion of thyroid hormones by stimulating TSHR, since the function of hCG is similar to the thyroid-stimulating hormone (TSH). The reason for the similarity is that the hCG and TSH molecules share similarities, as do the hCG and TSH receptors [14]. The level of hCG reaches its peak at the end of the first trimester, then decreases and remains stable during the second and third trimesters. The pattern of the change in free thyroxine (FT4) in the first trimester is the same as that of hCG. Because of the negative feedback effect of FT4, serum TSH in the first trimester (especially 7 to 12 weeks of gestation) drops to the lowest point and presents a mirror image of hCG peak [15-17]. One set of TSH data from a patient in Ruijin Hospital exhibited the same pattern as we described (Figure 1). The titer of serum TSH in $10-20 \%$ of normal pregnant women can be transiently subnormal, depending on the degree of the indirect suppression effect of circulating hCG [11].

2.2. Thyroxine-Binding Globulin (TBG). TBG functions as the main carrier of thyroxine (T4) or triiodothyronine (T3). 
Total T4 (TT4) or total T3 (TT3) includes both the free forms (FT4 or free T3, FT3) and the TBG-bound hormones. FT4 and FT3 represent bioavailable hormones, whereas TT4 and TT3 represent serum hormones. Both estrogens and silylation lead to an increase in TBG because the clearance of the more common silylation form is reduced compared to that of the nonsilylation form [15]. As a result, the TBG serum level will double compared with the nonpregnancy level. Serum TT4 and TT3 will increase correspondingly, but by no more than 1.5 times the upper level of the reference range of the nonpregnant state [11]. The fetal serum TBG level will be $100 \mathrm{nmol} / \mathrm{L}(5 \mathrm{mg} / \mathrm{L})$ at 12 weeks of gestation and will increase up to $500 \mathrm{nmol} / \mathrm{L}(25 \mathrm{mg} / \mathrm{L})$ when the infant is born [18]. The progressive increase in fetal serum FT4 levels along with TT4 levels indicates the maturation of the hypothalamic-pituitary-thyroid axis [19].

2.3. Iodine Intake. Many factors can lead to the increase in iodine requirements associated with pregnancy [20]. The loss of iodide is mainly caused by the increased clearance from the kidney. On the other hand, an increased consumption of iodine is caused by the needs of the fetus, increased production of TBG, and placental deiodination of thyroid hormones. The WHO [21], Endocrine Society [20], and American Thyroid Association [22] recommend an intake of potassium iodide of approximately $250 \mathrm{mcg}$ per day during pregnancy and lactation.

2.4. Thyroglobulin (TG). TG is the precursor of $\mathrm{T} 3$ and $\mathrm{T} 4$ and is stored in the colloid of thyroid follicles. When the synthesis of thyroid hormones is activated, TG will be absorbed into thyroid follicular cells and processed into T3 and T4. The typical variation pattern of TG includes an increase in early pregnancy, a stable level throughout midpregnancy, and another increase at 36 weeks of gestation. The serum TG level returns to the same level as that of the nonpregnant state after delivery [23]. If there was an insufficient iodine supply, more TG would be released into the blood directly without being processed. Thus, some recent studies have attempted to use serum TG levels as predictors of iodine deficiency, with some issues remaining unsolved [24]. To make TG function a reliable tool to identify iodine deficiency in pregnant women, these issues must be overcome [25].

2.5. Volume of Thyroid Gland. The volume of the thyroid gland may be influenced by many factors, such as iodine supplementation, sex, TSH, parity, genetics, age, anthropometric parameters, and smoking [26]. In nonpregnant individuals, thyroid volume correlates positively with age, bodyweight, $\mathrm{BMI}$, and total body water $[27,28]$. In regard to pregnancy, BMI has been found to be positively correlated with thyroid volume [29]. The reason pregnancy is characterized by hypervolemia is that total body water will increase from $6 \mathrm{~L}$ to $8 \mathrm{~L}$, and the extracellular water will also increase correspondingly since it composes the largest part of the total body water. Both body weight and BMI will increase with the accumulation of total water, and increase of body weight, BMI and total body water lead to an increase in thyroid volume
[14]. The effect of TSH on thyroid volume in pregnant women is controversial $[27,29]$. If the iodine supply is sufficient during pregnancy, the thyroid volume will not change significantly compared with that of the nonpregnant state [30]. Thyroid volume increases during pregnancy and decreases after delivery [29]. Based on these results, some researchers postulated that the increase in thyroid volume was caused by the increase in blood supply to the thyroid gland during pregnancy. This point of view is supported by the result of color flow Doppler sonography showing that intrathyroidal blood flow increases during pregnancy [31] and decreases in the year after delivery [29]. Thus, the authors hypothesized that the hemodynamic changes caused by delivery contributed to the changes in thyroid volume.

\section{Clinical Significance of TRAbs, TPOAbs, and TgAbs}

\subsection{TRAbs}

3.1.1. Subclasses of TRAbs. TSHR belongs to the family of G protein-coupled receptors (GPCRs). When TSHR is activated, all four subfamilies of $\mathrm{G}$ proteins (Gs, Gi/o, Gq/11, and $\mathrm{G} 12 / 13$ ) can be recruited. TSHR-Abs are commonly oligoclonal and of the IgG1 subclass, although other isotypes have been reported [32, 33]. According to the different influences on TSHR (including "stimulating," "blocking," and "neutral"), TRAbs can be divided into TSAbs, TBAbs, and N-TRAbs $[6,34]$. TSAbs are typical antibodies of GD [35]. When they bind to and activate TSHR, Gs and Gq/11 will be recruited [34]. The activation of $G$ protein-coupled signaling pathways leads to subsequent reactions in thyroid epithelial cells, including depression of apoptosis, proliferation, and the excessive production and secretion of the thyroid hormone. Then, the invalidation of the regulation by TSH results in the elevation of serum thyroid hormones, which leads to the signs and symptoms of GD [36].

The main pathology of atrophic thyroiditis (AT) is the apoptosis of thyroid epithelial cells mediated by $\mathrm{T}$ cells [37]. In AT patients, TRAbs bind to TSHR without activating it and prevent the combination of TSH and TSHR, resulting in hypothyroidism. This kind of antibody is called TBAbs. Although GD is characterized by an increase in TSAbs, TBAbs may appear simultaneously and contribute to the fluctuation in thyroid function [36]. Moreover, the transformation from GD to hypothyroidism may occur in a small number of GD patients due to the transformation of TSAbs to TBAbs. TBAbs-induced hypothyroidism and HT are clinically indistinguishable, except for the positivity for TRAbs in the first type.

Both TSAbs and TBAbs prevent TSH from binding to thyroid epithelial cells through occupying TSHR. Thus, they are also called "TSH-binding inhibitory immunoglobulin (TBII)" [38]. Two main methods are currently used to measure TRAbs: "receptor assays" measuring TBII and "bioassays" measuring the capacity of TRAbs to stimulate (TSAbs) or depress (TBAbs) the production of cAMP mediated by their ability to combine with TSHR [39]. 
N-TRAbs do not block the binding of TSH to TSHR, but they are able to aggravate local infiltration of inflammatory cells in the thyroid or posterior orbit by promoting the production of mitochondrial reactive oxygen species (mROS), which then induces cellular apoptosis [34]. Both mROS and apoptosis are implicated in the pathogenesis of thyroid autoimmunity and in Graves' orbitopathy (GO), and GO is characterized by proptosis, eyelid retraction, lagophthalmos, pressure in the orbit and periorbital swelling.

3.1.2. Clinical Application of TRAbs. As we have stated before, abnormal elevations of TPOAbs and TgAbs can be found in euthyroid populations. In contrast, abnormal increase of TRAbs can only be found in the sera of most GD patients and 10 to $15 \%$ of HT patients [36]. Their specificity for GD is close to $100 \%$, and their sensitivity is approximately $80 \%$ in liquid-phase TRAb assays [40]; thus, the abnormal elevation of TRAbs is also considered the hallmark of GD. They can also be used to diagnose and predict the outcome of GO in some patients [40]. $80 \%$ of GD can be diagnosed by clinical examination, laboratory examination (FT4, FT3, and TSH), thyroid ultrasound, and thyroid scintigraphy. However, measurement of TRAbs cannot be replaced for some special characteristics. These characteristics include high sensitivity, high efficacy for obtaining information regarding proper therapeutic methods, and relatively low costs [40]. In addition to diagnosing GD and GO, the abnormal elevation of TRAbs can be used for the differential diagnosis of painless thyroiditis, unilateral exophthalmos, subclinical hyperthyroidism, euthyroid GO, and other ambiguous diseases [41]. The abnormal elevation of TRAbs may help distinguish type 1 (autoimmune) amiodaroneinduced thyrotoxicosis from type 2 (inflammatory) [42]. After the application of antithyroid drugs (ATDs), the abnormal elevation of TRAbs can be used to predict GD recurrence risk [43]. TRAbs correlates positively also with thyroid vascularization at color-flow doppler and the odds of hyperthyroidism recurrence [44]. It has been reported that in GD patients developing hypothyroidism, TSAbs increase significantly 6 months after radioiodine treatment. Thus, the abnormal elevation of TSAbs is thought to be able to reflect thyroid damage caused by radioiodine and predict the outcome of thyroid function after radioiodine treatment [45]. Once basal serum TSH elevates abnormally and AITDs are considered, TBAbs may be the chief culprit, and the measurement of TBAbs may help establish the diagnosis of humoral immunity-induced hypothyroidism [46].

\subsubsection{Diseases Associated with the Abnormal Elevation of} TRAbs in the Field of Obstetrics and Gynecology. Thyroid autoimmunity is relevant to infertility, miscarriage, preterm delivery, and postpartum depression $[6,47]$. GD, the pathological basis of which is hyperthyroidism, has been shown to correlate with pregnancy. The undesirable pregnancy outcomes caused by hyperthyroidism are directly associated with the duration of thyrotoxicosis during pregnancy. Pregnancy-induced hypertension (PIH) accounts for the highest proportion of pregnancy complications caused by GD. Some researchers have found that the risk of eclampsia might increase by 5 times in hyperthyroid women without control compared to well-controlled women and nonhyperthyroid pregnant women $[48,49]$. The combination of hypertension and left ventricular dysfunction triggered by prolonged thyrotoxicosis may proceed to congestive heart failure. In addition, many complications, such as still birth, intrauterine growth restriction, gestational diabetes mellitus (GDM), preterm birth, cesarean delivery, and low-birth weight infants, are associated with overt hyperthyroidism $[50,51]$. The abnormal elevation of TRAbs may lead to poor growth and tachycardia of the fetus by crossing the placenta and stimulating the thyroid of the fetus [52]. Coincidentally, TBAbs may also cross the placenta and enter the circulation of the fetus, block the activation of TSHR, and induce neonatal transient hypothyroidism $[36,53]$. If infants are diagnosed with congenital [54] or neonatal [55] hypothyroidism, the abnormal elevation of TBAbs would be detected in the serum of their mothers. Also, TBAbs can be found in the neonates from hypothyroid mothers [6].

\subsection{TPOAbs}

3.2.1. Brief Introduction to TPOAbs. TPO functions as the core enzyme during the synthesis of thyroid hormones and is also the antigen of TPOAbs. The abnormal elevation of TPOAbs is most likely to be detected at the onset of thyroid dysfunction. Both TPOAbs and TgAbs mainly belong to the immunoglobulin (Ig) G class, mainly IgG1, with some IgG2, little IgG3, and tiny IgG4 subclasses. IgA class TPOAbs can be found in AITD patients at much lower levels [10, 33]. They are produced by lymphocytes that infiltrate the thyroid, and the titer has a positive correlation with the severity of infiltration [56]. Many pathological effects of the abnormal elevation of TPOAbs have been discovered by researchers. TPOAbs bind to TPO to form an immune complex (IC), which will trigger subsequent reactions, including antibodydependent cell-mediated cytotoxicity (ADCC) and complementmediated cytotoxicity, and then destroy thyroid epithelial cells [8]. Some studies have reported that TPOAbs were positive in 10 to $15 \%$ of the healthy population, and clinical hypothyroidism may develop from subclinical hypothyroidism in $2 \%$ of the healthy population. The TPOAb-positive rate varies with age, race, and ethnic background [57], and it can be higher in women of reproductive age. One study found that this rate ranged between $5.4 \%$ and $20 \%$ among those women, and it reached 14 to $33 \%$ in women with recurrent miscarriages and infertility [58].

Some factors may influence serum TPOAb titer. The effect of selenium to TPOAbs is controversial. Some scientists have found the use of selenium may lead to the drop in the titer of TPOAb [59-63], but other researchers have different opinions [64]. The effect of amiodarone on thyroid autoimmunity is still unclear [65]. Treatment of 131I or interferon- $\alpha$ will lead to the increase of TPOAbs $[10,66]$. The review of Rayman has mentioned that appearances of the abnormal elevation of TPOAbs and TgAbs are common in populations with a stable high iodine intake and those with mild and moderate iodine deficiency [67]. According to 
Snijders et al., in bipolar disorder (BD) patients, the prevalence of TPO-abs was unrelated to lithium use [68].

3.2.2. Clinical Application of TPOAbs. The abnormal elevation of the TPOAb titer is the gold standard for diagnosing HT and an assistant index for diagnosing GD. This index is sensitive and precise and prevails against fine-needle aspiration cytology of the thyroid when diagnosing HT [8]. TPOAb titer positively correlates with the TSH level, and it precedes the occurrence of thyroid failure. Thus, the abnormal elevation of TPOAbs is thought to be the marker of early thyroid dysfunction. TPOAbs are also considered to be able to reflect the severity of lymphocyte infiltration, and this ability is independent of hypothyroidism. TPOAb positivity is one of the risk factors for hypothyroidism in special conditions such as IFN- $\alpha$, IL- 2 , lithium, and amiodarone treatment and in Down's syndrome patients [56].

3.2.3. Diseases Associated with the Abnormal Elevation of TPOAbs in the Field of Obstetrics and Gynecology. TPOAbpositive women will have an increased risk of hypothyroidism if they were pregnant [56]. The risk of hypothyroidism and subclinical hypothyroidism will increase by 2 -fold after pregnancy if an individual is TPOAb-positive before pregnancy [69]. The appearance of the abnormal elevation of TPOAbs is also a risk factor for other medical diseases such as GDM [69] and anemia [70] during pregnancy. The relationship of the abnormal elevation of TPOAbs with obstetric complications is also nonnegligible since many studies have been reported by scientists. Associated complications include miscarriage, premature delivery, perinatal death, low delivery rate, polyhydramnios and placental abruption, and the abnormal elevation of TPOAbs are a risk factor for all of these complications [7,69-77]. The presence of the abnormal elevation of TPOAbs increases the rate of postpartum thyroid dysfunction (PPTD) [56], postpartum thyroiditis (PPT) [75], and postpartum depressive symptoms [78-80]. One recent study found a higher prevalence of infertility in TPOAb-positive euthyroid females [70]. However, some researchers have different opinions, and their study only revealed the association between premature rupture of fetal membrane (PROM), low birth weight, and the abnormal elevation of TPOAbs [81]. Other studies by Łukaszuk et al. and Plowden et al. did not find differences in fertilization, pregnancy rates, live birth rates, implantation, or miscarriage rates between TPOAb-positive and TPOAbnegative patients $[82,83]$.

It is worth mentioning that the fetus can also be influenced by the maternal abnormal elevation of TPOAbs. In the first 18 to 20 weeks of pregnancy, high concentrations of hCG will stimulate the thyroid gland to ensure that the developing fetus has sufficient thyroid hormone utilization [84]. However, TPOAb-positive women have impaired thyroid response to hCG stimulation [84]. Derakhshan et al. found that maternal TPOAb positivity was associated with lower mean child IQ in Rotterdam patients [84]. Findings of Ghassabian et al. imply that the elevated titers of TPOAbs during pregnancy impact increase risk of problem behavior in children, in particular, attention deficit/hyperactivity
[85]. The study of Pop et al. showed that children of pregnant women who had elevated titers of TPOAb but normal thyroid function are at risk for impaired development, including diminished verbal, perceptual, cognitive, and motor performance [86]. Wasserman et al. found that antenatal exposure to maternal $\mathrm{TPOaAb}$ during the third trimester of pregnancy is associated with impaired auditory development [87]. The relevance between the abnormal elevation of TPOAbs and offspring autism has also been reported by researcher [88]. The abnormal elevation of TPOAbs has not been reported as a causal factor of parity, period of gestation, or body weight [71].

\section{3. $T g A b s$}

3.3.1. Clinical Application of TgAbs. If autoimmune abnormalities occur in the thyroid, the abnormal elevation of TgAbs frequently appears along with that of TPOAbs [8]; thus, TgAbs are also regarded as markers of AITDs. Both TgAbs and TPOAbs are detected when the patient is suspected to have autoimmune hypothyroidism. However, $\mathrm{TgAb}$ alone in the absence of TPOAb is not significantly associated with thyroid disease [10, 57, 89]. In addition, TPOAb are more prevalent than TgAb in GD [10]. The sensitivity and specificity of TgAbs are not as good as those of TPOAbs in the diagnosis and prognosis of AITDs $[5,8,10]$. All of these factors may weaken the necessity of the measurement for TgAbs since the test for TPOAbs alone seems enough. Nevertheless, in the view of McLachlan et al., there are three reasons for measuring TgAb: Thyroid cancer, clinical versus subclinical disease, and insight into disease pathogenesis [10]. Women with isolated TgAb had significantly higher serum TSH levels compared to those in women without thyroid autoimmunity [90]. Thus according to "2014 European Thyroid Association Guidelines for the Management of Subclinical Hypothyroidism in Pregnancy and in Children", in the case of elevated TSH and negative TPOAb, $\mathrm{TgAb}$ should be measured [91]. The appearance of the abnormal elevation of TPOAbs and their powerful supplement TgAbs indicates the severity of thyroid lesions [8].

\subsubsection{Diseases Associated with the Abnormal Elevation of} TgAbs in the Field of Obstetrics and Gynecology. One study found that the abnormal elevation of titers of both TPOAbs and TgAbs in the first trimester of pregnancy were linked to an increase in morbidity due to hypertensive disorders of pregnancy, which was mainly caused by an increased risk of gestational hypertension, and the complications had no relationship with thyroid function. However, an association between the abnormal elevation of TgAbs and the risk of gestational hypertension or preeclampsia in the second trimester was not found [92]. Their results have been supported by another study that included 5805 women from 12 to 20 weeks of gestation, and the study did not find an association between abnormal elevations of thyroid antibodies (TPOAbs or TgAbs) and preeclampsia [93]. One study by Ordookhani et al. reported a positive correlation between transient neonatal hypothyroidism and elevated serum TgAb levels [94]. 


\section{The Variation in TRAbs, TPOAbs, and TgAbs during and after Pregnancy}

4.1. TRAbs

4.1.1. TRAb Trend during and after Pregnancy. The concentration of TRAb tends to decrease throughout pregnancy and increases after delivery. However, sometimes pregnant women may have stable or unexpectedly increased titers during pregnancy [95]. According to the pattern of TRAb change, it is thought that the decrease in TRAbs throughout pregnancy is caused by pregnancy-induced immunosuppression [6].

In the study of Gonzalez-Jimenez, 15 healthy and 45 pregnant GD women (20 were in recovery and 20 were well-managed with ATDs during pregnancy) were recruited. At first TRAb titers were in the normal range, but tended to decrease during late gestation. Even though TRAb titers of most individuals remained within the normal range, a significant rebound was observed in the late postpartum period [96]. In a study from Japan, researchers used four methods (first-, second-, and third-generation TBII assays and a bioassay) to measure the serum TRAb level in 23 women during pregnancy. They observed a decrease in both TRAbs and TSAbs during the pregnancy, independent of the assay method used [97]. A study by Abeillon-du Payrat et al. obtained the result of TBII from 42 pregnant women; among which, the levels decreased or remained stable in 36 women and the levels increased unexpectedly in the remaining six women [39]. A case report by Yoshida et al. observed that during the second pregnancy, the titer of serum TBAb and TRAb showed a remarkable fall, and their activities became undetectable after 36 weeks of gestation. One month after the second delivery, TBAb level increased with a concomitant rise of serum TRAb level [98]. The study of Amino et al. included six GD patients, and they found that activities of TSAbs and TBAbs decreased during pregnancy and increased after delivery [99]. Balucan et al. confirmed that the rebound of the TSAb level was most likely to occur four to twelve weeks postpartum. The rebound of the TSAb level might lead to the recurrence of or new-onset GD [66]. However, different results have occurred in some pregnant women. TRAbs can remain stable throughout pregnancy regardless of the incipient level since the course of GD is variable regardless of pregnancy [6].

4.1.2. The Switch of the Subclasses of TRAbs. The "quantitative" change in TRAbs has been observed as we have elaborated before. The "qualitative" change, or the variation in subclasses of TRAbs, has also been shown in both pregnant and nonpregnant states. Patients treated with levothyroxine (LT4) may confront the switch from TBAbs to TSAbs, while the reverse switch occurs in patients treated with ATDs [100]. The switch between the two kinds of antibodies may lead to the remission and deterioration of thyrotoxicosis in pregnancy. In a study that recruited fifteen pregnant GD women with low-dose ATD management and fourteen healthy pregnant women, serum levels of TRAbs (assessed by receptor assays), TSAbs, and TBAbs (by bioassays) were tested throughout pregnancy. All antibodies were negative in the healthy pregnant women, while TSAbs decreased significantly and TBAbs increased significantly with the fluctuation of TRAbs (TBII) in pregnant GD women [101]. Kung et al. recruited thirteen pregnant women with GD, and five of them without antithyroid management (patients 3, 5, 8, 10 , and 13) were TSAb-active in the first trimester. The level of TSAbs decreased in four patients, except patient 8, as pregnancy progressed. For TBAbs, three patients (patients 4, 5, and 9) were TBAb-positive in the first trimester. By the second and third trimesters, the number of TBAbpositive patients increased to eight and nine, respectively. TBAbs in seven patients remained positive four months after delivery [102]. The switch may also occur after delivery. The case report by Yoshida et al. showed the transformation from TBAbs to TSAbs after eight months postpartum [98].

4.1.3. The Significance of TRAb Monitoring. Pregnancy outcomes depend on metabolic status at delivery. If pregnant women with thyroid disorders are treated properly from the beginning of pregnancy and maintain euthyroid, they may have better pregnancy outcomes [103]. However, TRAb levels may change after the main treatment of GD (including thyroidectomy, ATDs, and I131 treatment) [104-107], and TRAb-positive euthyroid women do exist [41]. Even if the thyroid function indexes of pregnant women are normal, the fluctuation of TRAbs must be monitored since thyroid function examinations alone are not able to predict the effect of the abnormal elevation of TRAbs on both the mother and fetus. TRAbs can also be used to distinguish between the syndrome of gestational hyperthyroidism (SGH) and GD [108]. A maternal TRAb serum concentration $>5 \mathrm{IU} / \mathrm{L}$ (approximately 3 times the upper limit of normal for the assay) in the second and third trimester predicted neonatal hyperthyroidism [39, 109].

As for fetuses and infants, the study by Zakarija et al. reported that in one pregnant GD woman, serum TSAbs were lower during pregnancy than the levels in paired postpartum samples, but the infants were hyperthyroid after delivery. Therefore, they thought pregnancy might depress TSAbs; but once the effect was not sufficient, the influence of the abnormal elevation of TSAbs on the neonate's thyroid could not be avoided [110]. Researchers have proposed measuring TRAb levels during the third trimester of pregnancy to predict the risk of neonatal thyroid dysfunction [111].

The importance of monitoring TRAbs after delivery cannot be neglected either. TSAbs can be used as a predictor of postpartum onset or recurrence of GD since the elevation of TSAbs precedes the onset of the symptoms of GD when measured by means of sensitive bioassays [112]. Measurement of TRAbs postpartum can also be used to distinguish GD from postpartum thyroiditis [40].

\subsection{TPOAbs and TgAbs}

4.2.1. The Variation in TPOAbs and TgAbs during and after Pregnancy. The variation of TPOAbs and TgAbs over time are similar to those of TRAbs. Many researchers have observed that serum levels of TPOAbs and TgAbs gradually 


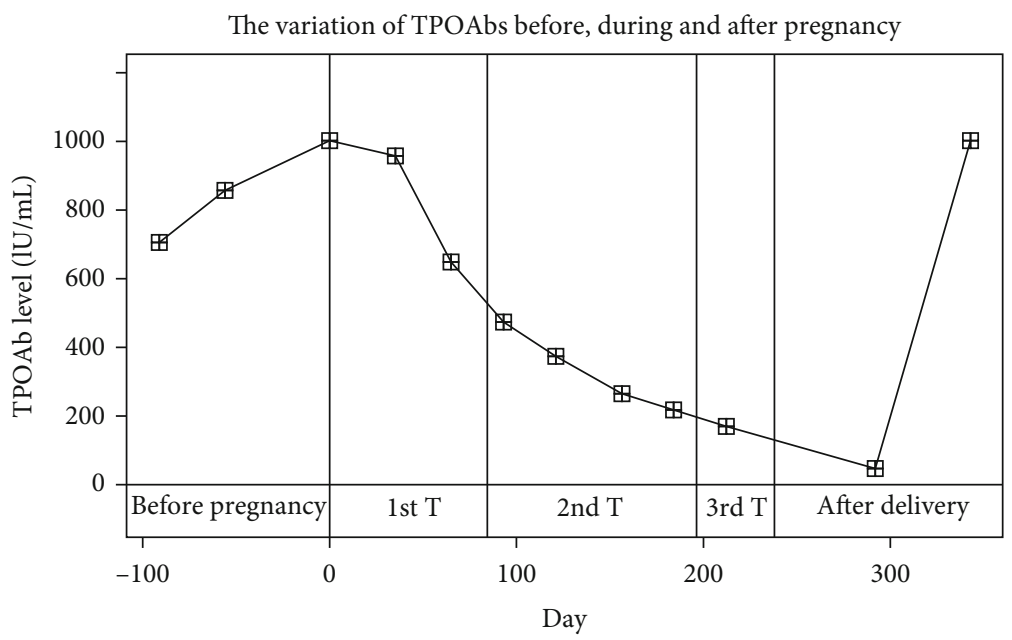

Figure 2: The variation in TPOAbs before, during, and after pregnancy. The curve is a set of data from one patient at Ruijin Hospital. The patient suffered from Hashimoto's thyroiditis, and the delivery date of her infant was July 2, 2018. The last menstrual period was November 6 , 2017, according to the gestational weeks and delivery date. TPOAb levels decreased during pregnancy and rebounded after delivery. T: trimester.

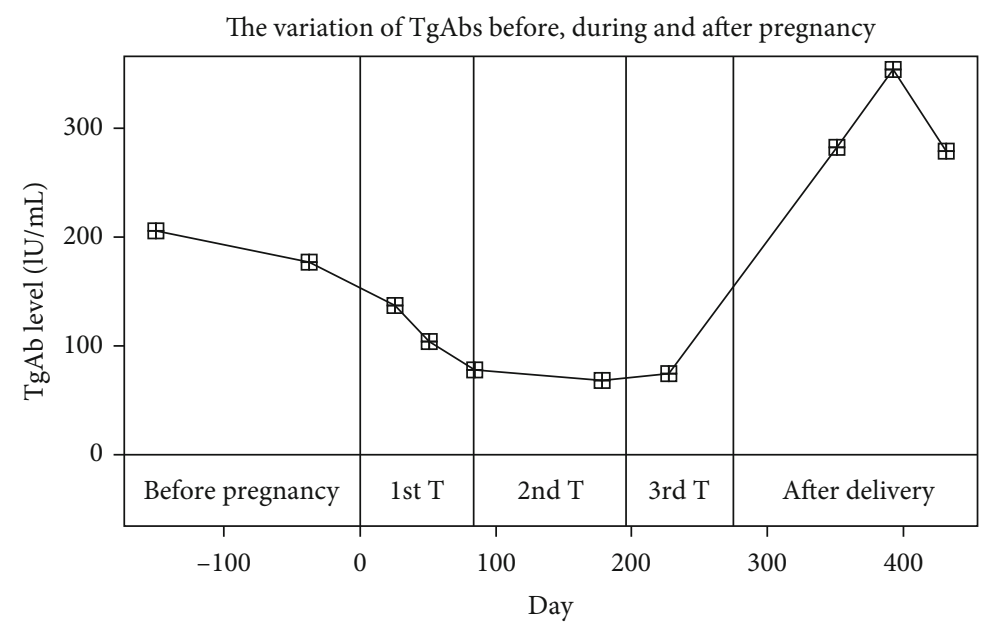

Figure 3: The variation in TgAbs before, during, and after pregnancy. The curve is a set of data from one patient at Ruijin Hospital. The delivery date of her infant was July 12, 2017. The last menstrual period was October 10, 2016, according to the gestational weeks and delivery date. The TgAb level decreased during pregnancy and rebounded after delivery. T: trimester.

decrease during pregnancy but rebound after delivery $[92,113-116]$. Their findings are the same as those we observed in the patients in Ruijin hospital (Figures 2 and 3). Smyth et al. recruited 25 pregnant women as the observation group and 57 nonpregnant women as the control group. They found that the TPOAb-positive rates of the control group and the rates in the first, second, and third trimesters of the observation group were $26.3 \%, 8.0 \%, 4.0 \%$, and $0 \%$, respectively [117]. In a recent study including forty TPOAb-positive euthyroid women, the average serum TPOAb levels were 209 $\pm 284.32 \mathrm{IU} / \mathrm{ml}, 112.34 \pm 126.08 \mathrm{IU} / \mathrm{ml}, 76.06 \pm 83.44 \mathrm{IU} / \mathrm{ml}$ , and $84.13 \pm 106.32 \mathrm{IU} / \mathrm{ml}$ in the first, second, and third trimester in pregnancy and postpartum period, respectively. The TPOAb titer decreased significantly in the second and third trimesters compared to that in the first trimester ( $p=0.016$ and 0.003 , respectively) [70]. Smyth et al. found that $\mathrm{TgAb}$-positive rates were $36.8 \%, 12.0 \%, 4.0 \%$, and $0 \%$ in the nonpregnant group and in the first, second, and third trimesters of the pregnancy group, respectively. The TgAbpositive rate of the pregnant group six weeks postpartum did not change compared to that of the third trimester (0\%) [117].

Some studies have focused on the postpartum period. Chen et al. allocated 26 women into a TPOAb-positive group and 182 women into a TPOAb-negative group. The postpartum TPOAb level increased significantly compared with the antepartum level in the TPOAb-positive group, but this result was not observed in the TPOAb-negative group [75]. Feldt-Rasmussen et al. found that TPOAbs increased six months postpartum in $36 \mathrm{TgAb}$-positive and TPOAbpositive mothers, and the increase was independent of PPTD [118]. According to the study of Smyth et al., the prevalence of TPOAbs was $21.7 \%$ at six weeks postpartum compared to 


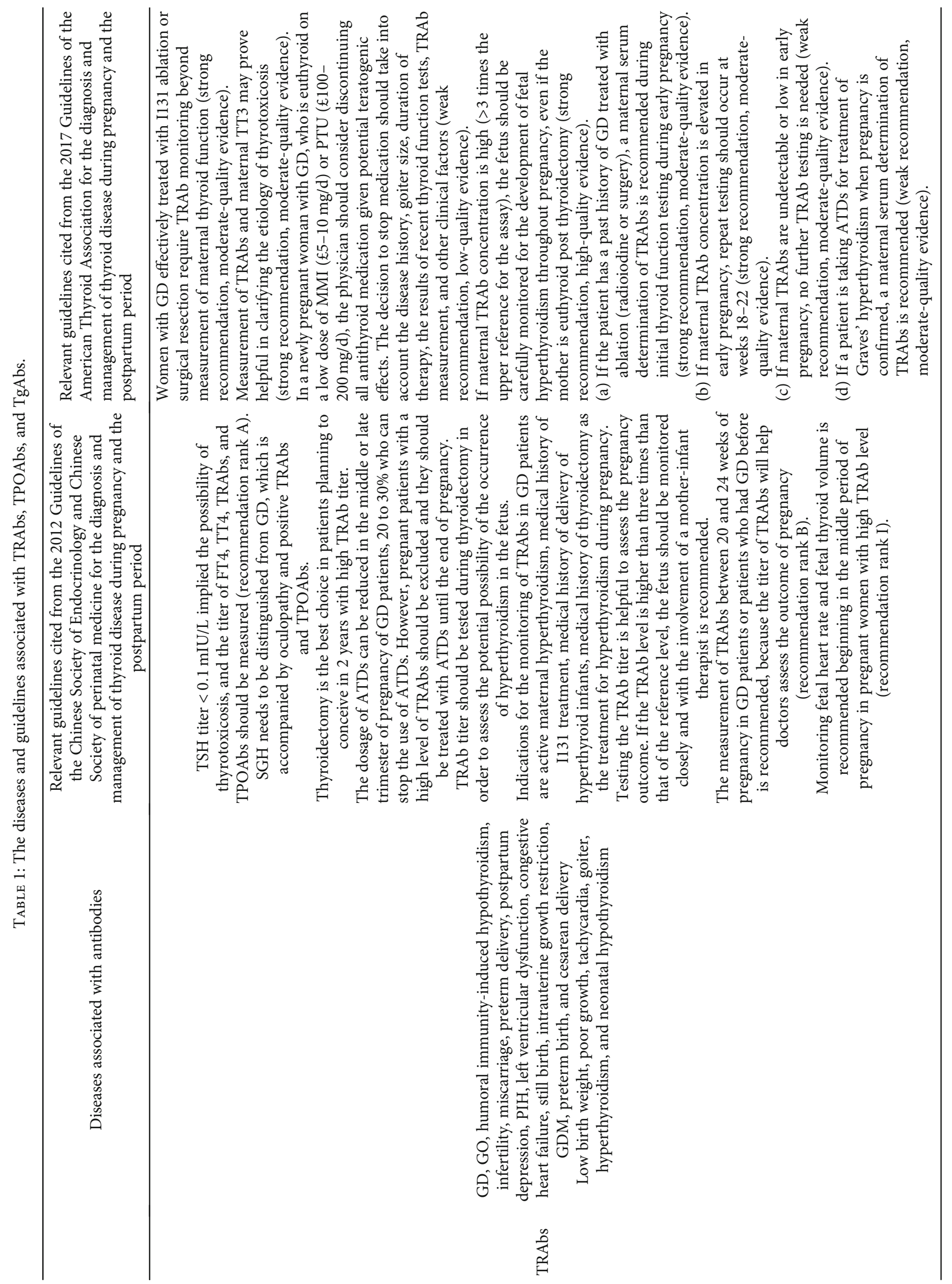




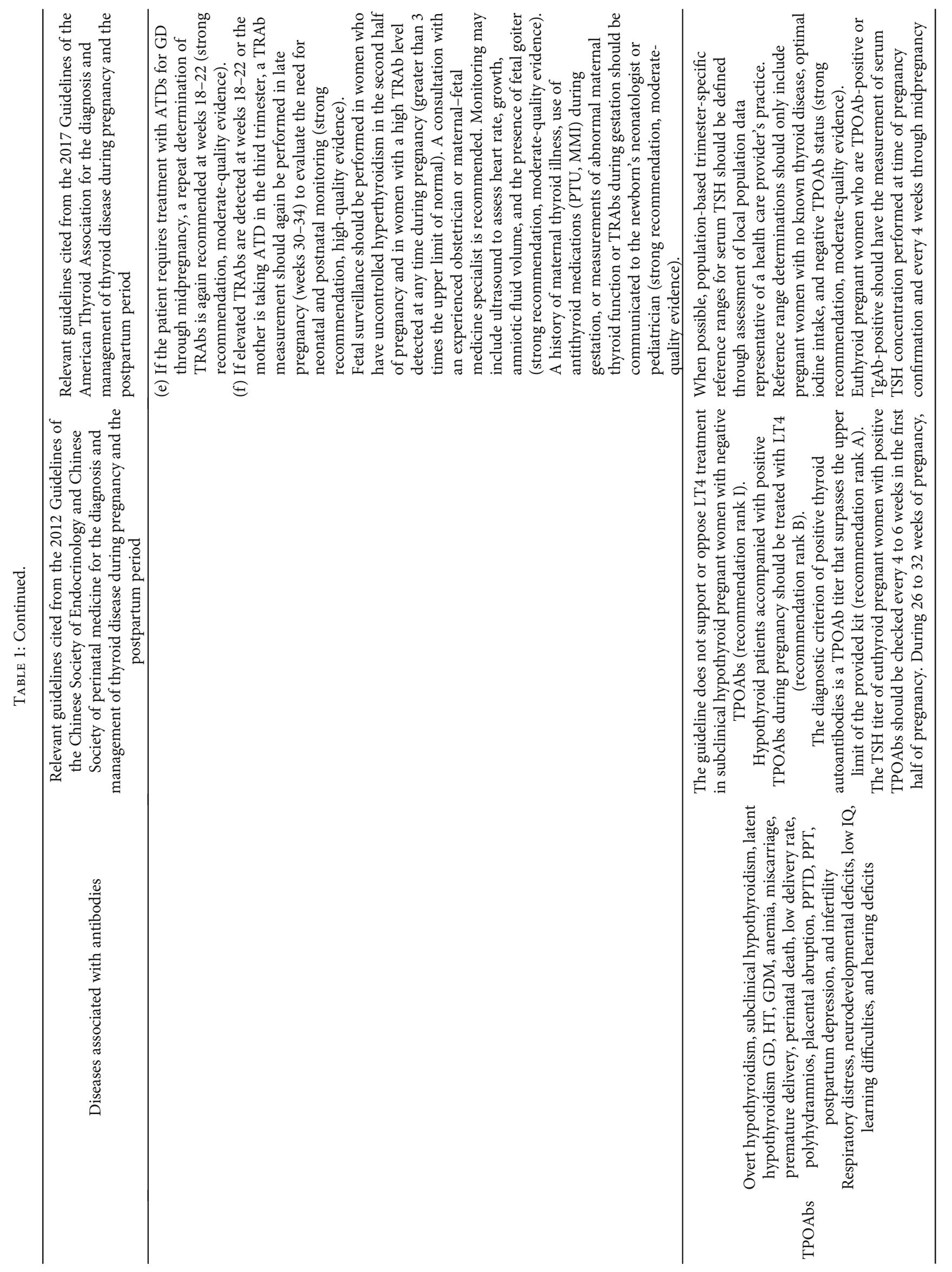




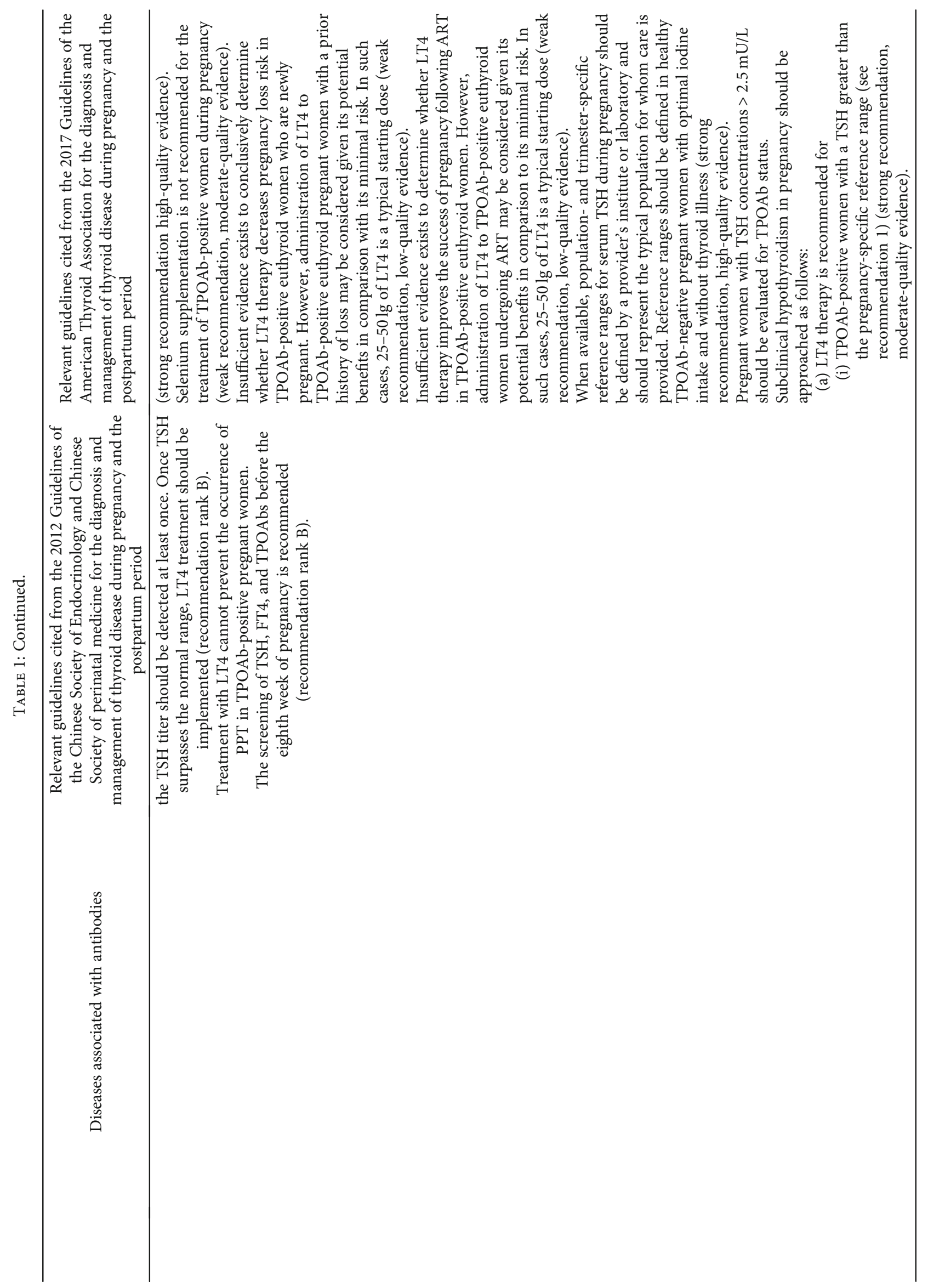




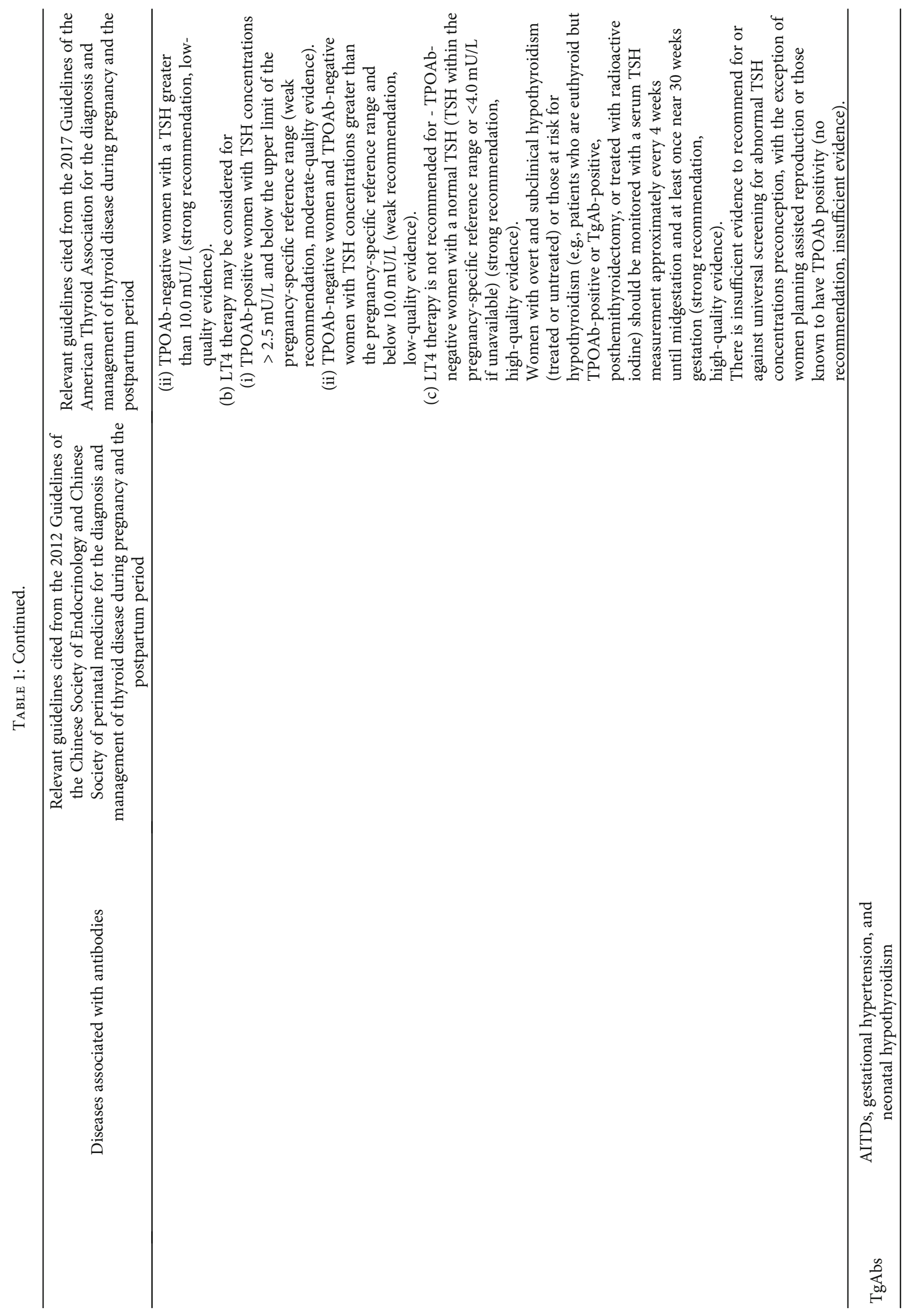


$0 \%$ in the third trimester [117]. According to a study by Parkes et al., the average TPOAb level increased from $20 \mathrm{KIU} / \mathrm{L}$ to $121 \mathrm{KIU} / \mathrm{L}$ throughout the postpartum year in the euthyroid TPOAb-positive group. In the PPT group, the TPOAb level reached the peak level of $181 \mathrm{KIU} / \mathrm{L}$ five months postpartum, compared to $28 \mathrm{KIU} / \mathrm{L}$ at delivery, and dropped to $118 \mathrm{KIU} / \mathrm{L}$ by twelve months postpartum [119].

4.2.2. The Significance of the Monitoring of TPOAbs and $T g A b s$. As we have stated before, the abnormal elevation of TPOAbs correlates with thyroid autoimmune disorders, and most of the patients are euthyroid $[57,73]$. In addition, the presence of the abnormal elevation of TPOAbs precedes the onset of thyroid dysfunction in adults [120]. Researchers have found that the elevation of TSH by the last trimester of pregnancy might occur in 15 to $20 \%$ of TPOAb-positive euthyroid women [121]. The monitoring of TPOAbs in euthyroid subjects may help predict the occurrence of hypothyroidism. TPOAbs increase the risk of hypothyroidism even if the TSH level is within the normal range [120]. Measuring TPOAbs can be beneficial for women preparing for pregnancy and pregnant women [56]. Testing for TgAbs is also helpful, as we explained in part two. Monitoring TPOAbs and TgAbs also helps to detect postpartum diseases. The presence of the abnormal elevation of TPOAbs in early pregnancy is regarded as the most powerful marker for predicting PPTD [80, 122]. TPOAbs are also used as a predictor of postpartum depression [79]. Even after LT4 treatment, the TPOAb level was negative in a few patients by 50 months postpartum [123]. It is still controversial whether the levels of TPOAbs and TgAbs will drop after the recovery of thyroid function in HT patients treated with LT4 [123-127]. For fetuses and infants, we have stated that abnormal elevation of TPOAbs is associated with neurodevelopmental defects; thus, it's necessary that attention is given to maternal thyroid function and TPOAb titer to prevent neurodevelopmental defects, which include lower IQ, learning difficulties, hearing deficits, and cerebral palsy [128-130].

\section{Conclusions}

According to what we have mentioned before, during pregnancy, many endocrinal physiological changes may occur. The abnormal elevations of TRAbs, TPOAbs and TgAbs may lead to certain adverse outcome to mothers and/or fetus. The most common change patterns of the three kinds of antibodies are that they decrease during pregnancy and increase again after delivery. The importance of the monitoring of the three antibodies is also reflected in both Chinese and American guidelines for the management of thyroid dysfunction during pregnancy and the postpartum period, and relevant clauses have been listed for the clinical practitioner's reference (Table 1) $[22,108]$. In addition, the diseases associated with the three antibodies that have been reported by other researchers are also included to emphasize the clinical value of those antibodies. Since thyroid antibodies do not necessarily imply that positive-women have thyroid dysfunction, therefore, thyroid antibodies should be measured along with thyroid function tests.
The diseases associated with TRAbs, TPOAbs, and TgAbs in the field of obstetrics and gynecology are listed in Table 1. Clauses relevant to those antibodies are cited from Guidelines of the American Thyroid Association for the diagnosis and management of thyroid disease during pregnancy and the postpartum period and Guidelines for the diagnosis and treatment of thyroid disease during pregnancy and the postpartum period (version 2012). Abbreviations: TRAbs: thyroid-stimulating hormone receptor antibodies; TPOAbs: thyroid peroxidase antibodies; TgAbs: thyroid globulin antibodies; GD: Graves' disease; GO: Graves' ophthalmopathy; PIH: pregnancy-induced hypertension; GDM: gestational diabetes mellitus; TSH: thyroid-stimulating hormone; FT4: free thyroxine; TT4: total thyroxine; SGH: syndrome of gestational hyperthyroidism; ATDs: antithyroid drugs; MMI: methimazole; PTU: propylthiouracil; HT: Hashimoto thyroiditis; PPTD: postpartum thyroid dysfunction; PPT: postpartum thyroiditis; IQ: intelligence quotient; LT4: levothyroxine; ART: assisted reproductive technology; AITDs: autoimmune thyroid diseases.

\section{Data Availability}

The data used to support the findings of this study are available from the corresponding author upon request.

\section{Disclosure}

Hans-Jürgen Gober present address is Pharmaceutical Outcomes Programme, British Columbia Children's Hospital, 938 West 28th Avenue, Vancouver BC, Canada.

\section{Conflicts of Interest}

The authors declare that there is no conflict of interest regarding the publication of this article.

\section{Acknowledgments}

This work was supported by grants from the National Natural Science Foundation of China (no. 31571196 and no. 30801502 to Ling Wang), the Program to Guide Medicine ("Yixueyindao") of the Shanghai Municipal Science and Technology Commission (no. 18401902200 and no. 15401932200 to Ling Wang), the Shanghai Program for Support of Leading Disciplines-Integrative Medicine (no. 20180101 and no. 20150407), the Research Foundation ("CR Sanjiu") of Obstetrics and Gynecology committee of Chinese Association of Integrated Traditional Chinese and Western Medicine (CR1901FC01 to Ling Wang), Shanghai Municipal Science and Technology Commission (20ZR1409100) the Shanghai Committee of the China Democratic League (no. 02054 to Ling Wang), the FY2008 JSPS Postdoctoral Fellowship for Foreign Researchers (P08471 to Ling Wang), and the Shanghai Pujiang Program (no. 11PJ1401900 to Ling Wang). 


\section{References}

[1] V. R. Moulton, "Sex hormones in acquired immunity and autoimmune disease," Frontiers in Immunology, vol. 9, p. 2279, 2018.

[2] Y. W. Zhang and N. W. Tong, "The interpretation of the newest guideline of thyroid dysfunction in pregnancy," Journal of practical obstetrics and gynecology, vol. 31, no. 12, pp. 899-902, 2015.

[3] G. J. Kahaly, L. Bartalena, L. Hegedüs, L. Leenhardt, K. Poppe, and S. H. Pearce, "2018 European Thyroid Association guideline for the management of graves' hyperthyroidism," European Thyroid Journal, vol. 7, no. 4, pp. 167-186, 2018.

[4] D. S. Ross, H. B. Burch, D. S. Cooper et al., "2016 American Thyroid Association guidelines for diagnosis and management of hyperthyroidism and other causes of thyrotoxicosis," Thyroid, vol. 26, no. 10, pp. 1343-1421, 2016.

[5] Chinese Society of Endocrinology, "Guidelines for the diagnosis and treatment of hypothyroidism in adults," Chinese Journal of Endocrinology and Metabolism, vol. 33, no. 2, pp. 167-180, 2017.

[6] I. Bucci, C. Giuliani, and G. Napolitano, "Thyroid-stimulating hormone receptor antibodies in pregnancy: clinical relevance," Front Endocrinol (Lausanne), vol. 8, p. 137, 2017.

[7] R. Bhattacharyya, K. Mukherjee, A. Das, M. R. Biswas, S. R. Basunia, and A. Mukherjee, "Anti-thyroid peroxidase antibody positivity during early pregnancy is associated with pregnancy complications and maternal morbidity in later life," J Nat Sci Biol Med, vol. 6, no. 2, pp. 402-405, 2015.

[8] D. J. Chen and Y. T. He, "The association between thyroid antibodies and pregnancy outcomes," $J$ Chinese journal of practical gynecology and obstetrics, vol. 29, no. 6, pp. 403406, 2013.

[9] J. Ruf and P. Carayon, "The molecular recognition theory applied to bispecific antibodies," Nature Medicine, vol. 1, no. 12, p. 1222, 1995.

[10] S. M. Mclachlan and B. Rapoport, "Why measure thyroglobulin autoantibodies rather than thyroid peroxidase autoantibodies?"” Thyroid, vol. 14, no. 7, pp. 510-520, 2004.

[11] S. Yalamanchi and D. S. Cooper, "Thyroid disorders in pregnancy," Current Opinion in Obstetrics \& Gynecology, vol. 27, no. 6, pp. 406-415, 2015.

[12] T. Tilburgs, S. A. Scherjon, and F. H. J. Claas, "Major histocompatibility complex (MHC)-mediated immune regulation of decidual leukocytes at the fetal-maternal interface," Journal of Reproductive Immunology, vol. 85, no. 1, pp. 58-62, 2010.

[13] P. W. Kincade, K. L. Medina, G. Smithson, and D. C. Scott, "Pregnancy: a clue to normal regulation of B lymphopoiesis," Immunology Today, vol. 15, no. 11, pp. 539-544, 1994.

[14] S. Gaberscek and K. Zaletel, "Thyroid physiology and autoimmunity in pregnancy and after delivery," Expert Review of Clinical Immunology, vol. 7, no. 5, pp. 697-707, 2011.

[15] A. R. Mcneil and P. E. Stanford, "Reporting thyroid function tests in pregnancy," Clinical Biochemist Reviews, vol. 36, no. 4, pp. 109-126, 2015.

[16] M. Moleti, F. Trimarchi, and F. Vermiglio, "Thyroid physiology in Pregnancy," Endocrine Practice, vol. 20, no. 6, pp. 589596, 2014.
[17] A. M. Goldman and J. H. Mestman, "Transient nonautoimmune hyperthyroidism of early pregnancy," Journal of Thyroid Research, vol. 2011, Article ID 142413, 11 pages, 2011.

[18] D. Springer, J. Jiskra, Z. Limanova, T. Zima, and E. Potlukova, "Thyroid in pregnancy: from physiology to screening," Critical Reviews in Clinical Laboratory Sciences, vol. 54, no. 2, pp. 102-116, 2016.

[19] M. Segni, Disorders of the thyroid gland in infancy, childhood and adolescence, L. J. Groot, G. Chrousos, K. Dungan, K. R. Feingold, A. Grossman, J. M. Hershman, C. Koch, M. Korbonits, R. Mclachlan, M. New, J. Purnell, R. Rebar, F. Singer, and A. Vinik, Eds., Endotext, South Dartmouth (MA), 2000.

[20] L. De Groot, M. Abalovich, E. K. Alexander et al., "Management of thyroid dysfunction during pregnancy and postpartum: an Endocrine Society clinical practice guideline," The Journal of Clinical Endocrinology and Metabolism, vol. 97, no. 8, pp. 2543-2565, 2012.

[21] M. Andersson, B. de Benoist, F. Delange, J. Zupan, and WHO Secretariat, "Prevention and control of iodine deficiency in pregnant and lactating women and in children less than 2years-old: conclusions and recommendations of the Technical Consultation," Public Health Nutrition, vol. 10, no. 12A, pp. 1606-1611, 2007.

[22] A. Stagnaro-Green, M. Abalovich, E. Alexander et al., "Guidelines of the American Thyroid Association for the diagnosis and management of thyroid disease during pregnancy and postpartum," Thyroid, vol. 21, no. 10, pp. 10811125, 2011.

[23] X. Zhang, C. Li, J. Mao et al., "Gestation-specific changes in maternal thyroglobulin during pregnancy and lactation in an iodine-sufficient region in China: a longitudinal study," Clinical Endocrinology, vol. 86, no. 2, pp. 229-235, 2017.

[24] R. Bilek, J. Cerovska, and V. Zamrazil, "The relationship between iodine intake and serum thyroglobulin in the general population," Physiological Research, vol. 64, no. 3, pp. 345353, 2015.

[25] Z. F. Ma and S. A. Skeaff, "Thyroglobulin as a biomarker of iodine deficiency: a review," Thyroid, vol. 24, no. 8, pp. 1195-1209, 2014.

[26] P. S. Hansen, T. H. Brix, F. N. Bennedbæk, S. J. Bonnema, K. O. Kyvik, and L. Hegedüs, "Genetic and environmental causes of individual differences in thyroid size: a study of healthy Danish twins," The Journal of Clinical Endocrinology and Metabolism, vol. 89, no. 5, pp. 2071-2077, 2004.

[27] J. M. Gómez, F. J. Maravall, N. Gómez, A. Gumà, and J. Soler, "Determinants of thyroid volume as measured by ultrasonography in healthy adults randomly selected," Clinical Endocrinology, vol. 53, no. 5, pp. 629-634, 2000.

[28] L. Hegedus, "Thyroid size determined by ultrasound. Influence of physiological factors and non-thyroidal disease," Danish Medical Bulletin, vol. 37, no. 3, pp. 249-263, 1990.

[29] P. Fister, S. Gaberšček, K. Zaletel, B. Krhin, K. Geršak, and S. Hojker, "Thyroid volume changes during pregnancy and after delivery in an iodine- sufficient Republic of Slovenia," European Journal of Obstetrics, Gynecology, and Reproductive Biology, vol. 145, no. 1, pp. 45-48, 2009.

[30] F. Azizi, A. Aminorroya, M. Hedayati, H. Rezvanian, M. Amini, and P. Mirmiran, "Urinary iodine excretion in pregnant women residing in areas with adequate iodine intake," Public Health Nutrition, vol. 6, no. 1, pp. 95-98, 2003. 
[31] P. Fister, S. Gaberšček, K. Zaletel, B. Krhin, K. Geršak, and S. Hojker, "Thyroid volume and intrathyroidal blood flow increase during pregnancy," Clinical Endocrinology, vol. 65, no. 6, pp. 828-829, 2006.

[32] R. Latif, S. A. Morshed, M. Zaidi, and T. F. Davies, "The thyroid-stimulating hormone receptor: impact of thyroidstimulating hormone and thyroid-stimulating hormone receptor antibodies on multimerization, cleavage, and signaling," Endocrinology and Metabolism Clinics of North America, vol. 38, no. 2, pp. 319-341, 2009.

[33] E. Frohlich and R. Wahl, "Thyroid autoimmunity: role of anti-thyroid antibodies in thyroid and extra-thyroidal diseases," Frontiers in Immunology, vol. 8, p. 521, 2017.

[34] S. A. Morshed, R. Ma, R. Latif, and T. F. Davies, "How one TSH receptor antibody induces thyrocyte proliferation while another induces apoptosis," Journal of Autoimmunity, vol. 47, pp. 17-24, 2013.

[35] K. Michalek, S. A. Morshed, R. Latif, and T. F. Davies, “TSH receptor autoantibodies," Autoimmunity Reviews, vol. 9, no. 2, pp. 113-116, 2009.

[36] T. Ando, R. Latif, and T. F. Davies, "Thyrotropin receptor antibodies: new insights into their actions and clinical relevance," Best Practice \& Research Clinical Endocrinology \& Metabolism, vol. 19, no. 1, pp. 33-52, 2005.

[37] G. Stassi, D. Di Liberto, M. Todaro et al., "Control of target cell survival in thyroid autoimmunity by $\mathrm{T}$ helper cytokines _via_regulation of apoptotic proteins," Nature Immunology, vol. 1 , no. 6 , pp. 483-488, 2000.

[38] N. Takasu and M. Matsushita, "Changes of TSH-Stimulation Blocking Antibody (TSBAb) and Thyroid Stimulating Antibody (TSAb) Over 10 Years in 34 TSBAb-Positive Patients with Hypothyroidism and in 98 TSAb-Positive Graves' Patients with Hyperthyroidism: Reevaluation of TSBAb and TSAb in TSH-Receptor-Antibody (TRAb)-Positive Patients," Journal of Thyroid Research, vol. 2012, Article ID 182176, 11 pages, 2012.

[39] J. A.-d. Payrat, K. Chikh, N. Bossard et al., "Predictive value of maternal second-generation thyroid-binding inhibitory immunoglobulin assay for neonatal autoimmune hyperthyroidism," European Journal of Endocrinology, vol. 171, no. 4, pp. 451-460, 2014.

[40] K. Zophel, D. Roggenbuck, and M. Schott, "Clinical review about TRAb assay's history," Autoimmunity Reviews, vol. 9, no. 10, pp. 695-700, 2010.

[41] T. F. Davies, E. Roti, L. E. Braverman, and L. DeGroot, "Thyroid-stimulating antibodies predict hyperthyroidisma," Journal of Clinical Endocrinology \& Metabolism, vol. 83, no. 11, pp. 3777-3781, 1998.

[42] E. Martino, L. Bartalena, F. Bogazzi, and L. E. Braverman, "The effects of amiodarone on the thyroid," Endocrine Reviews, vol. 22, no. 2, pp. 240-254, 2001.

[43] R. Wilson, J. H. McKillop, N. Henderson, D. W. Pearson, and J. A. Thomson, "The ability of the serum thyrotrophin receptor antibody (TRAb) index and HLA status to predict longterm remission of thyrotoxicosis following medical therapy for Graves' disease," Clinical Endocrinology, vol. 25, no. 2, pp. 151-156, 1986.

[44] R. Vita, F. Di Bari, S. Perelli, G. Capodicasa, and S. Benvenga, "Thyroid vascularization is an important ultrasonographic parameter in untreated Graves' disease patients," Journal of Clinical \& Translational Endocrinology, vol. 15, pp. 65-69, 2019.
[45] L. Chiovato, E. Fiore, P. Vitti et al., "Outcome of thyroid function in Graves' patients treated with radioiodine: role of thyroid-stimulating and thyrotropin-blocking antibodies and of radioiodine-induced thyroid damage," The Journal of Clinical Endocrinology and Metabolism, vol. 83, no. 1, pp. 40-46, 1998.

[46] T. Diana, P. Olivo, and G. Kahaly, "Thyrotropin receptor blocking antibodies," Hormone and Metabolic Research, vol. 50, no. 12, pp. 853-862, 2018.

[47] Y. Li, T. Xu, Q. Mo, W. Fu, and C. Yao, "Thyrotropin receptor antibody: a novel risk indicator for pregnancy loss," Clinical Biochemistry, vol. 64, pp. 44-48, 2019.

[48] L. K. Millar, D. A. Wing, A. S. Leung, P. P. Koonings, M. N. Montoro, and J. H. Mestman, "Low birth weight and preeclampsia in pregnancies complicated by hyperthyroidism," Obstetrics and Gynecology, vol. 84, no. 6, pp. 946-949, 1994.

[49] T. R. Easterling, B. C. Schmucker, K. L. Carlson, S. P. Millard, and T. J. Benedetti, "Maternal hemodynamics in pregnancies complicated by hyperthyroidism," Obstetrics and Gynecology, vol. 78, 3 Part 1, pp. 348-352, 1991.

[50] M. Phoojaroenchanachai, S. Sriussadaporn, T. Peerapatdit et al., "Effect of maternal hyperthyroidism during late pregnancy on the risk of neonatal low birth weight," Clinical Endocrinology, vol. 54, no. 3, pp. 365-370, 2001.

[51] N. Aggarawal, V. Suri, R. Singla et al., "Pregnancy outcome in hyperthyroidism: a case control study," Gynecologic and Obstetric Investigation, vol. 77, no. 2, pp. 94-99, 2014.

[52] J. M. Mckenzie and M. Zakarija, "Fetal and neonatal hyperthyroidism and hypothyroidism due to maternal Tsh receptor antibodies," Thyroid, vol. 2, no. 2, pp. 155-159, 1992.

[53] R. S. Brown, C. A. Alter, and A. Sadeghi-Nejad, "Severe unsuspected maternal hypothyroidism discovered after the diagnosis of thyrotropin receptor-blocking antibodyinduced congenital hypothyroidism in the neonate: failure to recognize and implications to the fetus," Hormone Research in Poediatrics, vol. 83, no. 2, pp. 132-135, 2015.

[54] R. S. Brown, P. Keating, and E. Mitchell, "Maternal thyroidblocking immunoglobulins in congenital hypothyroidism"," The Journal of Clinical Endocrinology and Metabolism, vol. 70, no. 5, pp. 1341-1346, 1990.

[55] V. P. Michelangeli, C. Poon, D. J. Topliss, and P. G. Colman, "Specific effects of radioiodine treatment on TSAb and TBAb levels in patients with Graves' disease," Thyroid, vol. 5, no. 3, pp. 171-176, 1995.

[56] M. F. Prummel and W. M. Wiersinga, "Thyroid peroxidase autoantibodies in euthyroid subjects," Best Practice \& Research. Clinical Endocrinology \& Metabolism, vol. 19, no. 1, pp. 1-15, 2005.

[57] J. G. Hollowell, N. W. Staehling, W. D. Flanders et al., "Serum TSH, T4, and thyroid antibodies in the United States population (1988 to 1994): National Health and Nutrition Examination Survey (NHANES III)," The Journal of Clinical Endocrinology and Metabolism, vol. 87, no. 2, pp. 489-499, 2002.

[58] K. Poppe, B. Velkeniers, and D. Glinoer, "The role of thyroid autoimmunity in fertility and pregnancy," Nature Clinical Practice. Endocrinology \& Metabolism, vol. 4, no. 7, pp. 394-405, 2008.

[59] R. Gartner, B. C. H. Gasnier, J. W. Dietrich, B. Krebs, and M. W. A. Angstwurm, "Selenium supplementation in patients with autoimmune thyroiditis decreases thyroid peroxidase antibodies concentrations," The Journal of Clinical 
Endocrinology and Metabolism, vol. 87, no. 4, pp. 1687-1691, 2002.

[60] D. Nacamulli, C. Mian, D. Petricca et al., "Influence of physiological dietary selenium supplementation on the natural course of autoimmune thyroiditis," Clinical Endocrinology, vol. 73, no. 4, pp. 535-539, 2010.

[61] R. Negro, G. Greco, T. Mangieri, A. Pezzarossa, D. Dazzi, and $H$. Hassan, "The influence of selenium supplementation on postpartum thyroid status in pregnant women with thyroid peroxidase autoantibodies," The Journal of Clinical Endocrinology and Metabolism, vol. 92, no. 4, pp. 1263-1268, 2007.

[62] L. H. Duntas, E. Mantzou, and D. A. Koutras, "Effects of a six month treatment with selenomethionine in patients with autoimmune thyroiditis," European Journal of Endocrinology, vol. 148, no. 4, pp. 389-393, 2003.

[63] E. E. Mazokopakis, J. A. Papadakis, M. G. Papadomanolaki et al., "Effects of 12 months treatment withl-selenomethionine on serum anti-TPO levels in patients with Hashimoto's thyroiditis," Thyroid, vol. 17, no. 7, pp. 609-612, 2007.

[64] G. Karanikas, M. Schuetz, S. Kontur et al., "No immunological benefit of selenium in consecutive patients with autoimmune thyroiditis," Thyroid, vol. 18, no. 1, pp. 7-12, 2008.

[65] Y. L. Liang, S. M. Huang, S. L. Peng et al., "Amiodaroneinduced thyrotoxicosis in a patient with autonomously functioning nodular goiter," The Annals of Pharmacotherapy, vol. 43, no. 1, pp. 134-138, 2009.

[66] F. S. Balucan, S. A. Morshed, and T. F. Davies, "Thyroid autoantibodies in pregnancy: their role, regulation and clinical relevance," Journal of Thyroid Research, vol. 2013, Article ID 182472, 15 pages, 2013.

[67] M. P. Rayman, "Multiple nutritional factors and thyroid disease, with particular reference to autoimmune thyroid disease," The Proceedings of the Nutrition Society, vol. 78, no. 1, pp. 34-44, 2019.

[68] G. J. L. J. Snijders, L. D. de Witte, D. van den Berk et al., "No association between anti-thyroidperoxidase antibodies and bipolar disorder: a study in the Dutch Bipolar Cohort and a meta-analysis," Psychoneuroendocrinology, vol. 112, article 104518, 2020.

[69] L. Lin, X. L. Zhang, and Y. Long, "Analysis of thyroid peroxidase antibody in early pregnancy," Genetics and Molecular Research, vol. 13, no. 3, pp. 5107-5114, 2014.

[70] M. Meena, S. Chopra, V. Jain, and N. Aggarwal, "The effect of anti-thyroid peroxidase antibodies on pregnancy outcomes in euthyroid women," Journal of Clinical and Diagnostic Research, vol. 10, no. 9, pp. QC04-QC07, 2016.

[71] R. Rajput, T. Yadav, S. Seth, and S. Nanda, "Prevalence of thyroid peroxidase antibody and pregnancy outcome in euthyroid autoimmune positive pregnant women from a tertiary care center in Haryana," Indian J Endocrinol Metab, vol. 21, no. 4, pp. 577-580, 2017.

[72] F. Ghafoor, M. Mansoor, T. Malik et al., "Role of thyroid peroxidase antibodies in the outcome of pregnancy," Journal of the College of Physicians and Surgeons-Pakistan, vol. 16, no. 7, pp. 468-471, 2006.

[73] S. Chan and K. Boelaert, "Optimal management of hypothyroidism, hypothyroxinaemia and euthyroid TPO antibody positivity preconception and in pregnancy," Clinical Endocrinology, vol. 82, no. 3, pp. 313-326, 2015.

[74] R. Negro, T. Mangieri, L. Coppola et al., "Levothyroxine treatment in thyroid peroxidase antibody-positive women undergoing assisted reproduction technologies: a prospective study," Human Reproduction, vol. 20, no. 6, pp. 1529-1533, 2005.

[75] X. Chen, B. Jin, J. Xia et al., "Effects of thyroid peroxidase antibody on maternal and neonatal outcomes in pregnant women in an iodine-sufficient area in China," International Journal of Endocrinology, vol. 2016, Article ID 6461380, 8 pages, 2016.

[76] Y. Han, L. J. Mao, X. Ge et al., "Impact of maternal thyroid autoantibodies positivity on the risk of early term birth: Ma'anshan Birth Cohort Study," Endocrine, vol. 60, no. 2, pp. 329-338, 2018.

[77] T. I. Korevaar, E. A. Steegers, V. J. Pop et al., "Thyroid autoimmunity impairs the thyroidal response to human chorionic gonadotropin: two population-based prospective cohort studies," The Journal of Clinical Endocrinology and Metabolism, vol. 102, no. 1, pp. 69-77, 2017.

[78] V. J. M. Pop, H. A. M. de Rooy, H. L. Vader, D. van der Heide, M. M. van Son, and I. H. Komproe, "Microsomal antibodies during gestation in relation to postpartum thyroid dysfunction and depression," Acta Endocrinologica, vol. 129, no. 1, pp. 26-30, 1993.

[79] M. Dama, M. Steiner, and R. V. Lieshout, "Thyroid peroxidase autoantibodies and perinatal depression risk: a systematic review," Journal of Affective Disorders, vol. 198, pp. 108-121, 2016.

[80] R. Wesseloo, A. M. Kamperman, V. Bergink, and V. J. M. Pop, "Thyroid peroxidase antibodies during early gestation and the subsequent risk of first-onset postpartum depression: a prospective cohort study," Journal of Affective Disorders, vol. 225, pp. 399-403, 2018.

[81] L. M. Chen, Q. Zhang, G. X. Si et al., "Associations between thyroid autoantibody status and abnormal pregnancy outcomes in euthyroid women," Endocrine, vol. 48, no. 3, pp. 924-928, 2015.

[82] K. Łukaszuk, M. Kunicki, P. Kulwikowska et al., “The impact of the presence of antithyroid antibodies on pregnancy outcome following intracytoplasmatic sperm injection-ICSI and embryo transfer in women with normal thyreotropine levels," Journal of Endocrinological Investigation, vol. 38, no. 12, pp. 1335-1343, 2015.

[83] T. C. Plowden, E. F. Schisterman, L. A. Sjaarda et al., "Subclinical hypothyroidism and thyroid autoimmunity are not associated with fecundity, pregnancy loss, or live birth," The Journal of Clinical Endocrinology and Metabolism, vol. 101, no. 6, pp. 2358-2365, 2016.

[84] A. Derakhshan, T. I. M. Korevaar, P. N. Taylor et al., “The association of maternal thyroid autoimmunity during pregnancy with child IQ," The Journal of Clinical Endocrinology \& Metabolism, vol. 103, no. 10, pp. 3729-3736, 2018.

[85] A. Ghassabian, J. J. Bongers-Schokking, Y. B. de Rijke et al., "Maternal thyroid autoimmunity during pregnancy and the risk of attention deficit/hyperactivity problems in children: the Generation R Study," Thyroid, vol. 22, no. 2, pp. 178186, 2012.

[86] V. J. Pop, E. de Vries, A. L. van Baar et al., "Maternal thyroid peroxidase antibodies during pregnancy: a marker of impaired child development?," The Journal of Clinical Endocrinology \& Metabolism, vol. 80, no. 12, pp. 3561-3566, 1995.

[87] E. E. Wasserman, K. Nelson, N. R. Rose et al., "Maternal thyroid autoantibodies during the third trimester and hearing 
deficits in children: an epidemiologic assessment," American Journal of Epidemiology, vol. 167, no. 6, pp. 701-710, 2008.

[88] A. S. Brown, H.-M. Surcel, S. Hinkka-Yli-Salomäki, K. Cheslack-Postava, Y. Bao, and A. Sourander, "Maternal thyroid autoantibody and elevated risk of autism in a national birth cohort," Progress in Neuro-Psychopharmacology \& Biological Psychiatry, vol. 57, pp. 86-92, 2015.

[89] L. Mehran, M. Tohidi, F. Sarvghadi et al., "Management of thyroid peroxidase antibody euthyroid women in pregnancy: comparison of the american thyroid association and the endocrine society guidelines," Journal of Thyroid Research, vol. 2013, Article ID 542692, 2013.

[90] D. Unuane, B. Velkeniers, E. Anckaert et al., “Thyroglobulin autoantibodies: is there any added value in the detection of thyroid autoimmunity in women consulting for fertility treatment," Thyroid, vol. 23, no. 8, pp. 1022-1028, 2013.

[91] J. Lazarus, R. S. Brown, C. Daumerie, A. HubalewskaDydejczyk, R. Negro, and B. Vaidya, "2014 European thyroid association guidelines for the management of subclinical hypothyroidism in pregnancy and in children," European Thyroid Journal, vol. 3, no. 2, pp. 76-94, 2014.

[92] Y. Han, L. J. Mao, X. Ge et al., “Thyroid autoantibodies in pregnancy are associated with hypertensive disorders of pregnancy: Ma'anshan Birth Cohort Study," Clinical Endocrinology, vol. 88, no. 6, pp. 928-935, 2018.

[93] T. Männistö, M. Vääräsmäki, A. Pouta et al., “Thyroid dysfunction and autoantibodies during pregnancy as predictive factors of pregnancy complications and maternal morbidity in later life," Obstetrical \& Gynecological Survey, vol. 65, no. 7, pp. 422-423, 2010.

[94] A. Ordookhani, P. Mirmiran, P. G. Walfish, and F. Azizi, "Transient neonatal hypothyroidism is associated with elevated serum anti-thyroglobulin antibody levels in newborns and their Mothers," The Journal of Pediatrics, vol. 150, no. 3, pp. 315-317.e2, 2007.

[95] S. De Leo and E. N. Pearce, "Autoimmune thyroid disease during pregnancy," The Lancet Diabetes and Endocrinology, vol. 6, no. 7, pp. 575-586, 2018.

[96] A. González-Jiménez, M. L. Fernández-Soto, F. EscobarJiménez, D. Glinoer, and L. Navarrete, "Thyroid function parameters and TSH-receptor antibodies in healthy subjects and Graves' disease patients: a sequential study before, during and after pregnancy," Thyroidology, vol. 5, no. 1, pp. 13-20, 1993.

[97] K. Kamijo, "TSH-receptor antibodies determined by the first, second and third generation assays and thyroid-stimulating antibody in pregnant patients with Graves' disease," Endocrine Journal, vol. 54, no. 4, pp. 619-624, 2007.

[98] S. Yoshida, J. Takamatsu, K. Kuma, and N. Ohsawa, "Thyroid-stimulating antibodies and thyroid stimulationblocking antibodies during the pregnancy and postpartum period: a case report," Thyroid, vol. 2, no. 1, pp. 27-30, 1992.

[99] N. Amino, Y. Izumi, Y. Hidaka et al., "No increase of blocking type anti-thyrotropin receptor antibodies during pregnancy in patients with Graves' disease," The Journal of Clinical Endocrinology and Metabolism, vol. 88, no. 12, pp. 58715874, 2003.

[100] S. M. Mclachlan and B. Rapoport, "Thyrotropin-blocking autoantibodies and thyroid-stimulating autoantibodies: potential mechanisms involved in the pendulum swinging from hypothyroidism to hyperthyroidism or vice versa," Thyroid, vol. 23, no. 1, pp. 14-24, 2013.
[101] A. W. Kung and B. M. Jones, "A change from stimulatory to blocking antibody activity in Graves' disease during pregnancy," The Journal of Clinical Endocrinology and Metabolism, vol. 83, no. 2, pp. 514-518, 1998.

[102] A. W. C. Kung, K. S. Lau, and L. D. Kohn, "Epitope mapping of TSH receptor-blocking antibodies in Graves' disease that appear during pregnancy," Journal Of Clinical Endocrinology \& Metabolism, vol. 86, no. 8, pp. 3647-3653, 2001.

[103] L. E. Davis, M. J. Lucas, G. D. V. Hankins, M. L. Roark, and F. G. Cunningham, "Thyrotoxicosis complicating pregnancy," American Journal of Obstetrics and Gynecology, vol. 160, no. 1, pp. 63-70, 1989.

[104] K. Sugino, T. Mimura, K. Toshima, O. Ozaki, and K. Ito, "Outcome of surgical treatment for Graves's disease and a correlation between its clinical course and values of TSH receptor antibodies (TRAb)," Nihon Geka Gakkai Zasshi, vol. 94, no. 6, pp. 611-614, 1993.

[105] K. Ahmed, K. Tomiyoshi, K. Fukazawa et al., "Measurement of serum TSH receptor antibodies in thyroid patients using TRAb Dade kits," Kaku Igaku, vol. 32, no. 7, pp. 695-701, 1995.

[106] A. Chiappori, D. Villalta, I. Bossert et al., "Thyrotropin receptor autoantibody measurement following radiometabolic treatment of hyperthyroidism: comparison between different methods," Journal of Endocrinological Investigation, vol. 33, no. 3, pp. 197-201, 2010.

[107] S. Atkinson, A. M. McGregor, P. A. T. Kendall-Taylor, M. M. Peterson, and B. R. Smith, "Effect of radioiodine on stimulatory activity of Graves' immunoglobulins," Clinical Endocrinology, vol. 16, no. 6, pp. 537-543, 1982.

[108] W. P. Teng et al., "Guidelines for the diagnosis and management of thyroid disease during pregnancy and the postpartum," J Chinese Journal of Endocrinology and Metabolism, vol. 28, no. 5, pp. 354-371, 2012.

[109] A. Besançon, J. Beltrand, I. le Gac, D. Luton, and M. Polak, "Management of neonates born to women with Graves' disease: a cohort study," European Journal of Endocrinology, vol. 170, no. 6, pp. 855-862, 2014.

[110] M. Zakarija and J. M. Mckenzie, "Pregnancy-associated changes in the thyroid-stimulating antibody of Graves' disease and the relationship to neonatal hyperthyroidism"," The Journal of Clinical Endocrinology and Metabolism, vol. 57, no. 5, pp. 1036-1040, 1983.

[111] D. C. Matthews and A. A. Syed, "The role of TSH receptor antibodies in the management of Graves' disease," European Journal of Internal Medicine, vol. 22, no. 3, pp. 213-216, 2011.

[112] N. Amino, H. Tada, and Y. Hidaka, "Postpartum autoimmune thyroid syndrome: a model of aggravation of autoimmune Disease," Thyroid, vol. 9, no. 7, pp. 705-713, 1999.

[113] A. Stagnaro-Green, S. H. Roman, R. H. Cobin, E. el-Harazy, S. Wallenstein, and T. F. Davies, "A prospective study of lymphocyte-initiated immunosuppression in normal pregnancy: evidence of a T-cell etiology for postpartum thsyroid dysfunction," The Journal of Clinical Endocrinology and Metabolism, vol. 74, no. 3, pp. 645-653, 1992.

[114] H. Tamaki, H. Katsumaru, N. Amino, H. Nakamoto, E. Ishikawa, and K. Mlyal, "Usefulness of thyroglobulin antibody detected by ultrasensitive enzyme immunoassay: a good parameter for immune surveillance in healthy subjects and for prediction of post-partum thyroid dysfunction," Clinical Endocrinology, vol. 37, no. 3, pp. 266-273, 1992. 
[115] N. Amino, R. Kuro, O. Tanizawa et al., "Changes of serum anti-thyroid antibodies during and after pregnancy in autoimmune thyroid diseases," Clinical and Experimental Immunology, vol. 31, no. 1, pp. 30-37, 1978.

[116] M. D’Armiento, H. Salabé, G. Vetrario, M. Scucchia, and A. Pachi, "Decrease of thyroid antibodies during pregnancy," Journal of Endocrinological Investigation, vol. 3, no. 4, pp. 437-438, 1980.

[117] P. P. A. Smyth, C. N. Wijeyaratne, W. N. Kaluarachi et al., "Sequential studies on thyroid antibodies during pregnancy," Thyroid, vol. 15, no. 5, pp. 474-477, 2005.

[118] U. Feldt-Rasmussen, M. H. Madsen, N. G. Rasmussen, L. Hegedüs, and P. Hornnes, "Antithyroid peroxidase antibodies during pregnancy and postpartum - relation to postpartum thyroiditis," Autoimmunity, vol. 6, no. 3, pp. 211-214, 2009.

[119] A. B. Parkes, S. Othman, R. Hall, R. John, C. J. Richards, and J. H. Lazarus, "The role of complement in the pathogenesis of postpartum thyroiditis," The Journal of Clinical Endocrinology and Metabolism, vol. 79, no. 2, pp. 395400, 1994.

[120] M. P. J. Vanderpump, W. M. G. Tunbrldge, J. M. French et al., "The incidence of thyroid disorders in the community: a twenty-year follow-up of the Whickham Survey," Clinical Endocrinology, vol. 43, no. 1, pp. 55-68, 1995.

[121] R. Negro, G. Formoso, T. Mangieri, A. Pezzarossa, D. Dazzi, and H. Hassan, "Levothyroxine treatment in euthyroid pregnant women with autoimmune thyroid disease: effects on obstetrical complications," The Journal of Clinical Endocrinology and Metabolism, vol. 91, no. 7, pp. 2587-2591, 2006.

[122] S. M. da Costa, L. S. Netto, C. M. Coeli, A. Buescu, and M. Vaisman, "Value of Combined Clinical Information and Thyroid Peroxidase Antibodies in Pregnancy for the Prediction of Postpartum Thyroid Dysfunction," American Journal of Reproductive Immunology, vol. 58, no. 4, pp. 344-349, 2007.

[123] M. Schmidt, M. Voell, I. Rahlff et al., "Long-term follow-up of antithyroid peroxidase antibodies in patients with chronic autoimmune thyroiditis (Hashimoto's thyroiditis) treated with levothyroxine," Thyroid, vol. 18, no. 7, pp. 755-760, 2008.

[124] J. H. Romaldini, M. M. Biancalana, D. I. Figueiredo, C. S. Farah, and P. C. Mathias, "Effect of L-thyroxine administration on antithyroid antibody levels, lipid profile, and thyroid volume in patients with Hashimoto's thyroiditis," Thyroid, vol. 6, no. 3, pp. 183-188, 1996.

[125] D. Y. Aksoy, U. Kerimoglu, H. Okur et al., "Effects of prophylactic thyroid hormone replacement in euthyroid Hashimoto's thyroiditis," Endocrine Journal, vol. 52, no. 3, pp. 337-343, 2005.

[126] L. Hegedüs, J. M. Hansen, U. Feldt-Rasmussen, B. M. Hansen, and M. Høier-Madsen, "Influence of thyroxine treatment on thyroid size and anti-thyroid peroxidase antibodies in Hashimoto's thyroiditis," Clinical Endocrinology, vol. 35, no. 3, pp. 235-238, 1991.

[127] S. Padberg, K. Heller, K. H. Usadel, and P. M. SchummDraeger, "One-year prophylactic treatment of euthyroid Hashimoto's thyroiditis patients with levothyroxine: is there a benefit?," Thyroid, vol. 11, no. 3, pp. 249-255, 2001.

[128] J. E. Haddow, G. E. Palomaki, W. C. Allan et al., "Maternal thyroid deficiency during pregnancy and subsequent neuropsychological development of the child," The New
England Journal of Medicine, vol. 341, no. 8, pp. 549555, 1999.

[129] B. Fernandez Rodriguez and A. J. Perez Diaz, "Evaluation of a follow up protocol of infants born to mothers with antithyroid antibodies during pregnancy," The Journal of Maternal-Fetal \& Neonatal Medicine, vol. 31, no. 3, pp. 312-319, 2018.

[130] E. I. Ekinci, W. L. Chiu, Z. X. Lu et al., “A longitudinal study of thyroid autoantibodies in pregnancy: the importance of test timing," Clinical Endocrinology, vol. 82, no. 4, pp. 604610, 2015. 